NBER WORKING PAPER SERIES

\title{
DO STOCK PRICE BUBBLES INFLUENCE CORPORATE INVESTMENT?
}

\author{
Simon Gilchrist \\ Charles P. Himmelberg \\ Gur Huberman
}

Working Paper 10537

http://www.nber.org/papers/w10537

\author{
NATIONAL BUREAU OF ECONOMIC RESEARCH \\ 1050 Massachusetts Avenue \\ Cambridge, MA 02138 \\ June 2004
}

We are grateful to Anna Scherbina for providing us with data, and we thank Andy Abel, Tobias Adrian, Ignazio Angeloni, Brian Cherno,, Wei Jiang, Bob King, Jim Mahoney, David Marshall, Asani Sarkar, Jeremy Stein, and seminar participants at the Federal Reserve Bank of New York, Federal Reserve System Meetings, Federal Reserve Bank of San Francisco, Colorado University, Columbia University, Harvard University, University of Brescia, the ASSA meetings, and the JME/Gerzensee Conference on Behavioral Macroeconomics for helpful comments and suggestions. We are also grateful to Brian Cherno $\alpha$ for excellent research assistance. The views expressed are those of the authors and do not necessarily reflect the positition of the Federal Reserve Bank of New York or the Federal Reserve System. The views expressed herein are those of the author(s) and not necessarily those of the National Bureau of Economic Research.

(C2004 by Simon Gilchrist, Charles P. Himmelberg, and Gur Huberman. All rights reserved. Short sections of text, not to exceed two paragraphs, may be quoted without explicit permission provided that full credit, including (C) notice, is given to the source. 
Do Stock Price Bubbles Influence Corporate Investment?

Simon Gilchrist, Charles P. Himmelberg, and Gur Huberman

NBER Working Paper No. 10537

May 2004

JEL No. E22, G31, G32, D92

\section{ABSTRACT}

Building on recent developments in behavioral asset pricing, we develop a model in which dispersion of investor beliefs under short-selling constraints drives a firm's stock price above its fundamental value. Managers optimally respond to the stock market bubble by issuing new equity.

The bubble reduces the user-cost of capital and increase real investment. Using the variance of analysts' earnings forecasts as a proxy for the dispersion of investor beliefs, we find strong empirical support for the model's key prediction that increases in dispersion cause increases in new equity issuance, Tobin's Q, and real investment.

Simon Gilchrist

Department of Economics

Boston University

270 Bay State Road

Boston, MA 02215

and NBER

sgilchri@bu.edu

Charles P. Himmelberg

Federal Reserve Bank of New York

and Columbia University

gcph15@columbia.edu

Gur Huberman

Columbia University

gh16@columbia.edu 


\section{Introduction}

Research on asset prices increasingly challenges the view that asset prices equal fundamental value. In particular, finance theory is increasingly sympathetic to the idea that stock price bubbles are possible. In this paper, we consider their consequences for corporate investment and financing behavior. Some theories of bubbles rely on a common bias in investors' beliefs. But there also exists an important class of theories in which bubbles can arise even when beliefs are, on average, unbiased. If pessimists are constrained in their ability to short, then prices disproportionately reflect beliefs of optimists, and thus rise above their fundamental value. ${ }^{2}$ That stock price bubbles could arise under these conditions has been pointed by Miller (1977) and Chen, Hong and Stein (2002), among others. Refinements and extensions have also been examined, including the effect of dynamic speculative trading (Harrison and Kreps, 1978) and the endogenous formation of heterogeneous beliefs (Scheinkman and Xiong, 2003). ${ }^{3}$ This is the type of stock price bubble on which we focus in this paper.

What should corporate managers do when they believe that their firms' stock prices are inflated for the above reasons? In particular, what should they do when, as in the above setting, investor beliefs are disperse, and the pessimists cannot short the stock ${ }^{4}$ We make two key observations. First, unlike other agents, firms are unconstrained in their ability to sell short - they can simply issue new shares. Second, in contrast to textbook models of corporate finance, the above environment implies that firms face a downward-sloping demand curve for new share issues. Consequently, since the firm is a monopolist in the supply of its own shares, and since resale in the

\footnotetext{
${ }^{2}$ Of course, this class of models does not preclude the possibility that average beliefs are also biased. Such a bias provides a second source of bubbles that we do not examine.

${ }^{3}$ See also Allen, Morris, and Shin (2003). For surveys of behavioral asset pricing models more generally, see Barberis and Thaler (2002), Hirshleifer (2001) and Shleifer (2000).

${ }^{4}$ Stein (1996) explores rational capital budgeting in the presence of irrational market prices. Focusing on the firm's invetment decision, he assumes that the market has a biased view of the firm's future. In this class of problems, our paper considers the special case when market pricing irrationalities are generated by heterogeneous beliefs and short-sale constraints (as in Miller, 1977).
} 
secondary market prevents price discrimination, the optimal quantity of shares issued is that which equates marginal revenue with marginal cost. This occurs where price is above fundamental value. Thus, somewhat counter-intuitively, the bubble survives the firm's attempt to exploit it.

Our model also considers the consequences for real investment. In general, the management's decision as well as the market's valuation should reflect the expected use of funds. If 100 percent of the proceeds were invested in cash, for example, investors would presumably agree on the value of that portion of the firm's balance sheet. In our model, the heterogeneous beliefs among investors apply only to the firm's operating assets. This assumption eliminates the manager's incentive to use the proceeds from the issuance of over-valued stock to invest in cash, marketable securities, dividend payment, or retirement of the firm's own debt. There is, however, a real distortion; managers over-invest in operating assets because the market overvalues them.

The model's quantitative predictions are perhaps surprising. Most notably, it is possible to generate large stock price bubbles with relatively small distortions to financing activity and real investment. Roughly speaking, this happens when the demand curve for new shares is steep. Analogous to the monopolist's problem, a steep demand curve implies a high price over marginal cost and therefore a large bubble. The large bubble is accompanied by a small quantity of new shares issued and therefore a small reduction in the cost of capital. This arguably provides a good description of many stocks that were often described as bubbles during the tech boom of the late 1990s. Despite sky-high valuations, firms like Amazon and Yahoo, for example, issued a surprisingly small fraction of total equity to the public. As we will argue, such behavior is consistent with our model. For policy makers, our findings suggest that while deviations of stock prices from fundamentals can have real consequences, large stock price bubbles may be less distortionary than one might otherwise think. 
Our empirical strategy builds on Diether, Malloy and Scherbina (2002) who use the dispersion of a firm's stock analysts' forecasts of its future earnings as a proxy for the dispersion of investors' beliefs about the fundamental value of the firm. ${ }^{5}$ Diether et al. report that high-dispersion stocks have abnormally low future returns, consistent with the view that such firms are overvalued and that their equity prices move slowly toward their fundamental value. This variable is particularly well-suited for our purposes because clean proxies for bubbles are hard to find. For example, using the recent equity price run-up to identify a bubble is problematic because the bubble cannot be distinguished from increased optimism regarding the firm's investment opportunities. Such optimism may well be rational and should lead to equity flotation and increased real investment by the firm.

We first consider the time series evidence regarding dispersion of analysts forecasts for the corporate sector and show that they comove with Tobin's Q, net new share issuance, and real investment. We show that Nasdaq firms, in particular, experienced a run-up in dispersion during the late 1990s through 2001 that was accompanied by higher values of Tobin's Q, an increase in new share issues, and higher levels of real investment. This pattern is consistent with the predictions of our model.

We further investigate the predictions of our model by estimating the effect of changes in dispersion on investment, Tobin's $\mathrm{Q}$ and net equity issuance within a panel-data VAR framework. To control for the possible correlation between changes in dispersion and investment opportunities, we consider the effect of shocks to dispersion that are orthogonal to innovations in the marginal product of capital. ${ }^{6}$ Conditional on fixed time and firm effects, the impulse response functions of the estimated model show that positive dispersion shocks give rise to higher values of Tobin's Q, higher equity issuance, and higher real investment. This pattern is uniformly consistent with

\footnotetext{
${ }^{5}$ See also Park (2001).

${ }^{6}$ If disagreement increased by shocks to the investment opportunity set, then disagreement would contain information about investment opportunities, and could thus explain the pattern observed in aggregate means.
} 
the predictions of our model.

Finally, we compute variance decompositions to assess the quantitative importance of dispersion shocks. As a fraction of the explainable variation in the data, we find that dispersion shocks have a large impact on equity issuance, a modest impact on Tobin's Q, and a relatively small impact on real investment. In our model, large bubbles do not necessarily imply large investment distortions. In our empirical findings, this is in fact the case.

Recent research in finance provides additional empirical support for our model assumptions. Most notably, Diether, Malloy, and Scherbina (2002) report that high dispersion forecasts low future returns. A portfolio of stocks in the highest quintile of dispersion underperforms a portfolio of stocks in the lowest quintile of dispersion by 9.48\% percent per year. Chen, Hong and Stein (2002) report related evidence. Instead of using data on analysts' forecasts, they define a measure of "breadth" based on the number of funds prevented from taking a short position due to legal constraints. They find that "short-constrained" stocks have low future returns. Additional evidence on the price effects of short-sale constraints is provided by Lamont and Jones (2002). They show that stocks that were expensive to short during the 1920s and 30s delivered lower returns than other stocks. Using more recent data, Ofek and Richardson (2003) report that the spring 2000 collapse of the internet bubble coincided with a substantial supply of new shares created by the expiration of lock-up restrictions. Finally, D'Avolio's (2003) detailed description of the market for borrowed stock provides extensive direct evidence that short selling is costly.

Polk and Sapienza (2002) also attempt to measure the distortionary effect of stock price bubbles on real investment. They argue that new equity issues, discretionary earnings accruals, and lagged returns can be used as proxies for bubbles. Using Tobin's Q to control for investment opportunities, they find that, consistent with their predictions, these bubble proxies enter positively and statistically significantly 
in a regression for investment. ${ }^{7}$ While many of their results are consistent with our model predictions, our model also highlights a potential problem with their use of the $\mathrm{Q}$ model as a framework for estimating the effects of bubbles on investment. Namely, Tobin's Q cannot be used to control for investment opportunities because Q also depends on the bubble. In theory, this endogeneity problem is serious enough to produce coefficient estimates of the "wrong" sign on the bubble proxy. Our empirical strategy avoids this econometric problem by constructing a measure of exogenous dispersion shocks.

Panageas (2004) similarly argues that Tobin's Q cannot be used to proxy for investment opportunities. In his model, the marginal investor has infinite wealth. As a result, share issuance has no marginal effect on price, new share issuance is indeterminate, and Tobin's Q is a sufficient statistic for investment even in the presence of bubbles. By contrast, in our model, the downward-sloping demand for shares drives a wedge between average and marginal Q, and Tobin's Q is no longer a sufficient statistic for investment.

Evidence in favor of a downward sloping demand for shares is documented by Asquith and Mullins (1986), who report that equity prices drop following announcements of secondary stock offerings. Additional evidence is offered in Scholes (1972) and Holthausen et al. (1990), who study block trades, Shleifer (1986), who studies additions to the S\&P 500 index, and Loderer et al. (1991), who conclude that "on balance, the evidence suggests that issuing firms cannot treat the demand for their stock as if it were perfectly elastic".

Several other empirical papers are related in various ways. Motivated in part by the possibility of bubbles in stock prices, M $\phi$ rck, Shleifer and Vishny (1991) and Blanchard, Rhee and Summers (1993) compare the responsiveness of investment to Tobin's Q and fundamentals and broadly conclude that investment is driven primar-

\footnotetext{
${ }^{7}$ Polk and Sapienza (2002) also point out that abnormally high investment levels may be caused in part by stock bubbles, in which case they should predict low subsequent returns. This is indeed what they find.
} 
ily by fundamentals. ${ }^{8}$ Chirinko (1996) and Chirinko and Schaller (2001) implement similar tests by including both fundamental and market $\mathrm{Q}$ measures, but conclude instead that the evidence favors the existence of bubbles. Erickson and Whited (1999) and Bond and Cummins (2000) estimate investment-Q equations and speculate that stock price bubbles are a likely source of measurement error in Tobin's Q. ${ }^{9}$

In the remainder of the paper, we begin by exploring the implications for firm behavior of a simple equilibrium model of heterogeneous investor beliefs under shortselling constraints. In section 3 , we briefly describe the data and econometric approach, followed by a description of our empirical results. Section 4 concludes.

\section{A Model of Real Investment, Equity Issuance, and Bubbles}

In this section, we develop a simple model of firm behavior when investors with heterogeneous beliefs face short-selling constraints in the equity market. First, we aggregate heterogenous portfolio demands and show that aggregate demand for new shares is increasing in the degree of dispersion in beliefs. Second, we consider the share issuance and real investment decisions of a rational manager who seeks to maximize the objective value of the firm on behalf of existing shareholders. We assume that the manager is fully aware of the bubble and takes into account the effect of equity issuance on the stock price when making such decisions.

We show that an increase in dispersion leads to an increase in the equilibrium

\footnotetext{
${ }^{8}$ Baker, Stein, and Wurgler (2002) similarly ask whether some firms are intrinsically more dependent on equity for their external financing, and thus more sensitive to stock prices.

${ }^{9}$ Less closely related to ours are papers that examine the behavioral biases of executives rather than market prices, and explores the potential impact on corporate investment decisions. Heaton (1999) develops a model in which CEOs are both overconfident and overoptimistic. Malmendier and Tate (2002) use the timing of stock option exercise to measure overconfidence. Bertrand and Schoar (2002) report evidence that CEOs appear to have managerial "styles" that accompany them when they change jobs. By contrast with these papers, we assume managers have rational (unbiased) expectations.
} 
price bubble and an increase in net equity issuance. As a result, the user cost of capital falls and investment increases. Finally, the rise in investment combined with the increase in the bubble imply a higher equilibrium value of Tobin's Q. We conclude by discussing the model's implications for empirical work.

\subsection{The Demand for New Share Issues}

We assume that an investor's demand for shares is driven by the difference between perceived value and current price. For simplicity, we rule out speculative demand based on the difference between the current and likely future price of shares. In contrast to investors, the manager's beliefs about firm value are unbiased. We refer to this unbiased or objective assessment as the firm's "fundamental" value, denoted by $V$.

Heterogeneous investor valuations are denoted by $v V$, where $v \in[0, \infty]$ is a random variable that measures idiosyncratic variation in investors beliefs. Let $P$ denote the market value (price) of the firm. We assume the investor's portfolio demand for a firm's shares (i.e., the fraction of the investor's wealth invested in the firm) is given by

$$
\omega_{v}=\gamma(v V-P)
$$

This functional form for portfolio demand can be derived from a model in which investors have CARA utility and fundamental value $(V)$ is normally distributed. In this case, $\gamma$ represents the constant of absolute risk aversion scaled by the variance of fundamental value, and as such, may vary across firms. Cross-firm variation in $\gamma$ may also arise owing to differences in attitudes toward risk, such as limits to diversification. For example, firms prone to agency problems may require less diversified investors for incentive reasons and therefore a higher $\gamma \cdot{ }^{10}$ As we show below, the size of real

\footnotetext{
${ }^{10}$ Although a number of empirical studies attempt to compute the price elasticity of demand with respect to share issues, these numbers are difficult to interpret because it is difficult to control for news effects. We are not aware of any studies providing estimates from which we could infer the
} 
distortions depends on $\gamma$.

Multiplying equation (1) by investor wealth, $W$, and dividing by the market value of the firm, $P$, translates the investor's demand from a fraction of investor wealth to a fraction of firm value, $n_{v}=\gamma W\left(v B^{-1}-1\right)$, where $B=P / V$. We refer to $B$ - the ratio of price over fundamental value - as the bubble. Without loss of generality, we assume $W=1$.

Under short-selling constraints, the only investors who take non-zero positions in the stock are those for whom $v V \geq P$, or $v \geq B$. Hence, assuming $v$ has the distribution function $F(v ; \sigma)$, the aggregate demand for shares is

$$
n^{d}(B ; \sigma, \gamma)=\gamma \int_{B}^{\infty}\left(v B^{-1}-1\right) d F(v ; \sigma)
$$

To characterize this demand function we assume that $v$ is log-normally distributed with $\ln v \sim N\left(-0.5 \sigma^{2}, \sigma^{2}\right)$, so that $E(v)=1$. This normalization imposes the assumption that average beliefs are unbiased. It also implies that net demand for shares is zero when the ratio of price to fundamental value equals one and short-sale constraints are not binding. Let $\phi$ and $\Phi$ denote the p.d.f. and c.d.f. of the standard normal distribution respectively, and $b$ denote a normalized $\log$ transformation of $B$ :

$$
b \equiv \frac{\ln B+0.5 \sigma^{2}}{\sigma}
$$

Using properties of the log-normal distribution, equation (2) can be expressed as

$$
n^{d}(B ; \sigma, \gamma)=\gamma(1-\Phi(b))\left[\frac{h(b)}{h(b-\sigma)}-1\right]
$$

where $h(b)$ denotes the hazard rate for the standard normal distribution:

$$
h(b) \equiv \frac{\phi(b)}{1-\Phi(b)}
$$

model parameter $\gamma$. 
The first term in equation (4) measures the mass of market participants as a function of the bubble $B$. The second term in equation $(4), h(b) / h(b-\sigma)$, measures the average demand conditional on market participation. ${ }^{11}$ Because the hazard rate is strictly increasing, the ratio $h(b) / h(b-\sigma)$ is greater than one, hence market demand is strictly positive for $B>0$. As the bubble increases, market participation falls, while demand conditional on participation rises. On net, the first effect dominates, and demand for share falls.

We can invert the demand curve in equation (4) to solve for $B$ as a function of the number of shares issued. Denote the fraction of total shares supplied to the public by $n$, and let $B(n ; \sigma)$ denote the inverse demand function. In a working paper version of this paper, we show that this inverse demand curve slopes downward in the size of the equity issue, and that it shifts outward in response to an increase in dispersion. ${ }^{12}$ Specifically, the partial derivatives satisfy:

$$
B_{n}=\frac{-B^{2}}{\gamma(1-\Phi(b-\sigma))}<0,
$$

and

$$
B_{\sigma}=B h(b-\sigma)>0
$$

The derivatives in equations (5) and (6) lead to simple expressions for the respective demand elasticities. In particular, the inverse-price elasticity of demand $\eta_{n} \equiv-\frac{\partial \ln B}{\partial \ln n}$ is

$$
\eta_{n}=1-\frac{h(b-\sigma)}{h(b)} .
$$

Since the ratio $h(b-\sigma) / h(b)$ is bounded between zero and one, the inverse-demand

\footnotetext{
${ }^{11}$ To obtain equation 4 we note $(1-\Phi(B-\sigma)=E(v \mid v>B) \operatorname{Pr}(v>B)$ so that equation 2 may be written as

$$
n^{d}(B ; \sigma, \gamma)=\gamma\left[(1-\Phi(b-\sigma)) B^{-1}-(1-\Phi(b))\right]
$$

(see Johnson, Kotz and Balikrishnan (1994)). Equation 3 may be equivalently expressed as $B=$ $\phi(b-\sigma) / \phi(b)$. Inserting this expression into $n^{d}(B ; \sigma)$ yields the result.

${ }^{12}$ The appendix establishes a number of mathematical results used in this section.
} 
curve is inelastic over its entire range. The semi-elasticity of the bubble with respect to dispersion, $\eta_{\sigma} \equiv \frac{\partial \ln B}{\partial \sigma}$, is

$$
\eta_{\sigma}=h(b-\sigma)
$$

The shift in demand caused by an increase in dispersion depends on the degree of truncation, and hence the hazard rate of the normal distribution evaluated at the bubble. To understand the implications of such a demand shift for investment, we now turn to the firm's problem.

\subsection{Equity Issuance and the Equilibrium Price Bubble}

Given the inverse-demand function $B(n ; \sigma)$, we can now formally consider the firm's problem. Let the expected value of installed capital, $K$, be given by

$$
V(K)=E[\Pi(K, \theta)]+(1-\delta) K,
$$

where $\theta$ represents a shock to the profitability of capital. To install new capital, the firm incurs an adjustment cost $\frac{1}{2} \psi K^{2}$. We assume managers recognize mispricing and choose $K$ to maximize the true value of the firm from the perspective of old shareholders. ${ }^{13}$ Managers can finance this investment using risk-free debt at the rate $r$, or they can issue new equity by selling a fraction $n$ of the firm's equity. They can invest the proceeds in $K$, or pay them out as a dividend to the old shareholders. The market value of equity is given by $B(n ; \sigma) V(K)$, so proceeds from new equity issues are given by the discounted value of the new shareholders' claim, or

$$
X=\frac{1}{1+r} n B(n ; \sigma) V(K)
$$

\footnotetext{
${ }^{13}$ For example, managers might own a stake in the firm for incentive reasons, in which case their incentives are to act on behalf of old rather than new shareholders.
} 
Thus the firm's optimization problem is:

$$
\max _{I, X, n}-K-\frac{1}{2} \psi K^{2}+X+(1-n) \frac{1}{1+r} V(K)
$$

subject to equation (4). Note that the future value of the firm in equation (10) is multiplied by $1-n$ to reflect the dilution of old shareholders.

The first-order condition for equity issuance derived from equation (10) implies:

$$
B(n ; \sigma)+n B_{n}(n ; \sigma)=1
$$

Applying the result that the inverse demand curve is downward sloping $\left(B_{n}<0\right)$, it follows that the bubble satisfies $B>1$ when the firm is issuing new shares $(n>0)$.

The firm is a monopolist in the supply of its own shares, hence the share-issuance decision is analogous to the standard monopoly problem. In equation (11) marginal cost is unity while marginal benefit equals $B(n ; \sigma)+n B_{n}(n ; \sigma)$. These costs and benefits are proportional to $V(K)$ which drops out of the equation. ${ }^{14}$ The result that the bubble is positive in equilibrium is analogous to the result that a monopolist always sets price above marginal cost. Thus a key feature of our model is that the firm issues new shares but never drives the bubble down to its fundamental value.

Applying equation (7), the equilibrium price satisfies ${ }^{15}$

$$
B(\sigma)=\frac{h(b)}{h(b-\sigma)}
$$

\footnotetext{
${ }^{14}$ Because share issuance represents a dilution of the claims of existing share holders, the marginal cost of issuance is proportional to $V(K)$, the fundamental value of the firm. Similarly, because heterogenous beliefs are defined relative to fundamental value, the marginal benefit of issuance is also proportional to $V(K)$.

${ }^{15}$ From the monopolist's viewpoint, the bubble is analogous to the markup of price over marginal cost, where the marginal cost of new share issues is unity. The equilibrium bubble in equation 11 can be expressed as a relationship between the markup and the inverse demand elasticity:
}

$$
B=\frac{1}{1-\eta_{n}} .
$$


Equation (12) defines a unique mapping $B(\sigma)$, that is, for any $\sigma>0$ there is a unique equilibrium price $B .{ }^{16}$ Given the equilibrium price $B(\sigma)$, the equilibrium value of equity issuance is determined by

$$
n(\sigma, \gamma)=\gamma(1-\Phi(b))(B(\sigma)-1)
$$

This equilibrium is depicted in figure 1 , which plots the market demand curve and the marginal revenue curve for new equity issuance for the parameter values $\sigma=0.5$ and $\gamma=1$. Equilibrium equity issuance is denoted by $n^{*}$. For these parameter values, the equilibrium stock price is overvalued by nearly $50 \%$, and the firm sells around $14 \%$ of its equity to the public. Note that the equilibrium stock price in equation (12) is solely determined by the level of dispersion, whereas the equilibrium size of the equity issues depends not only on dispersion but also on the parameter $\gamma$. Thus, for any size bubble, the size of the equity issue is arbitrarily small or large, depending on the value of $\gamma$.

We next consider the effect of an increase in dispersion on the equilibrium bubble $B$ and equity issuance $n$. Totally differentiating equation (12) yields

$$
\frac{d B}{d \sigma}=\frac{B(b[h(b-\sigma)+\sigma-h(b))]+\sigma[h(b)-b])}{(\sigma+[h(b-\sigma)+\sigma-h(b)])}>0 .
$$

Thus an increase in dispersion causes an increase in the equilibrium size of the bubble. ${ }^{17}$ We further establish that

$$
\frac{d \ln B}{d \sigma}<h(b-\sigma)=\eta_{\sigma}
$$

\footnotetext{
${ }^{16}$ Equation 12 implies that the equilibrium value $B(\sigma)$ is independent of other model parameters, notably the demand parameter $\gamma$. Thus, a monopolist facing a demand curve of the form specified in equation 4 chooses a constant markup that only depends on demand characteristics through $\sigma$, the degree of consumer heterogeneity. This result can be applied to a variety of consumer settings characterized by a log-normal distribution of underlying demand characteristics.

${ }^{17}$ To establish the inequality $\frac{d B}{d \sigma}>0$ we rely on the fact that the hazard rate $h(b)$ is log-concave so that $h(b-\sigma)+\sigma-h(b)>0$. See the appendix for full details of the derivation of equations 14 and 15 .
} 
Figure 1: Equilibrium share price $(B)$ and share issuance $(n)$.

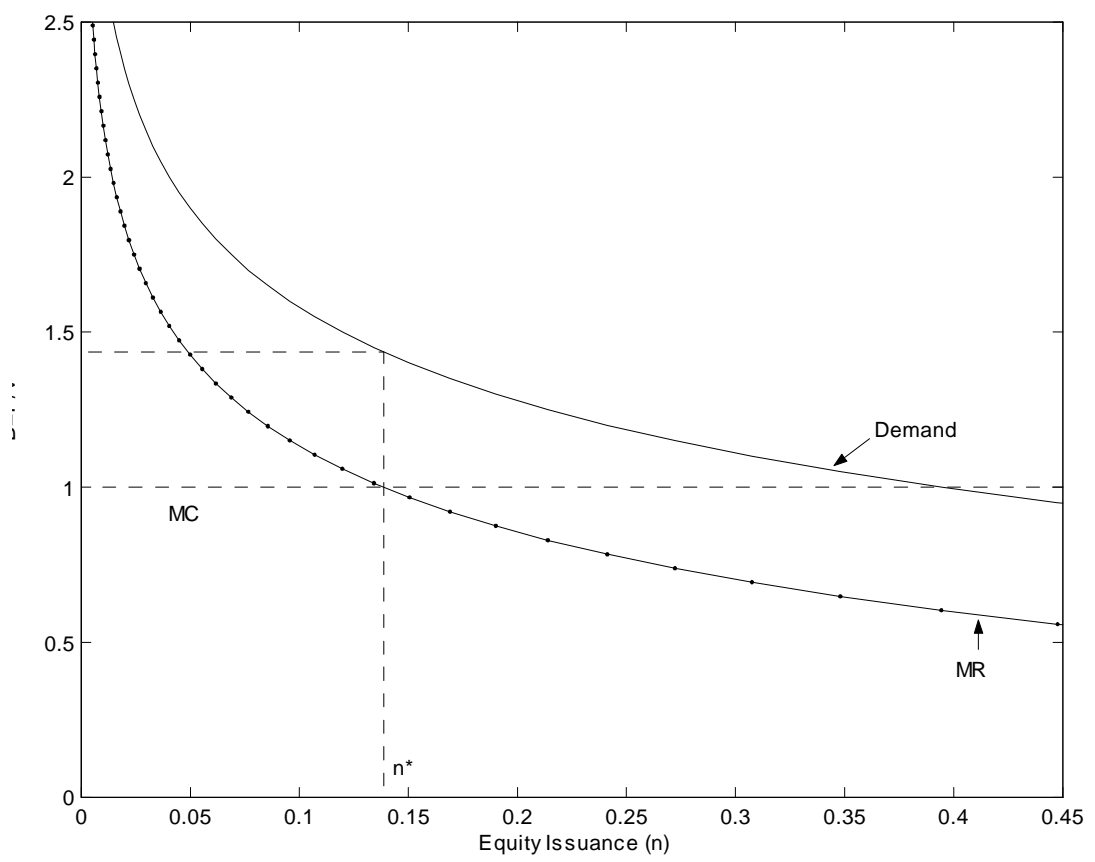

In words, the equilibrium response of the bubble to an increase in dispersion is less than the implied elasticity obtained from the demand curve. Intuitively, a firm issues new equity in response to an increase in dispersion, partially offsetting the effect of a rise in $\sigma$ on price. To formally see the effect of an increase in dispersion on equity issuance, we totally differentiate equation (13) to obtain

$$
\frac{d n}{d \sigma}=\gamma \frac{[(1-\Phi(b-\sigma))]}{B}\left(h(b-\sigma)-\frac{d \ln B}{d \sigma}\right)>0 .
$$

In Figure 2, we show the effect of an increase in dispersion from $\sigma=0.5$ to $\sigma=0.7$. This causes an outward shift in the market demand for shares and increases the equilibrium size of the bubble. It also increases the fraction of equity issued (from $n^{*}$ to $n^{* *}$ ). As shown in equation (13), equity issuance depends on both the average demand per participant, $\gamma(B-1)$, and the percentage of market participants, $1-\Phi(b)$. In our model, the rise in demand per participant increases enough to offset 
Figure 2: The effect of an increase in dispersion.

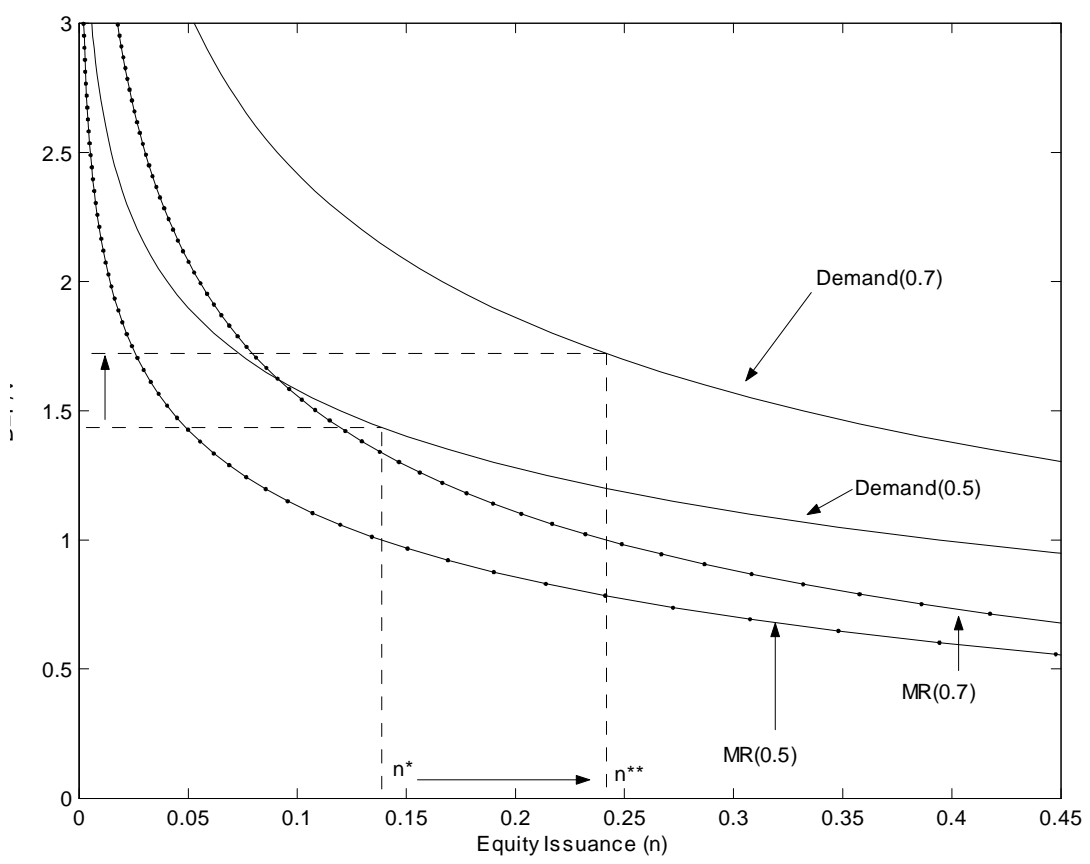

Figure 3:

the drop in market participation, and an increase in dispersion causes an increase in share issuance.

\subsection{Investment and the Cost of Capital}

A convenient feature of our model formulation is that it allows us to consider the equilibrium behavior of share issuance and stock pricing without directly considering the firm's investment decision. As we now show, in equilibrium, an increase in dispersion leads to a lower cost of capital and an increase in investment.

The first-order condition with respect to capital (from the firm's problem in equations (9) and (10)) implies the (modified) $Q$ equation

$$
1+\psi K=\frac{1+n(B-1)}{1+r} V_{k} .
$$


For the case where there is no bubble $(B \equiv 1)$, equation (17) simplifies to $1+\psi K=$ $\frac{1}{1+r} V_{k}$. This is the usual first-order condition for investment, which says that the firm invests up to the point where the marginal cost of investment, $1+\psi K$, equals the discounted expected marginal value of capital, $\frac{1}{1+r} V_{k}$ (or marginal $Q$ ).

To see the effect of the bubble on investment, we first consider the case of no adjustment costs $(\psi=0)$. Using equation (8) to substitute for $V_{k}$, we can re-write equation (17) as

$$
E\left(\Pi_{k}\right)=\frac{1+r}{1+n(B-1)}-(1-\delta) .
$$

This expression allows us to interpret the effect of bubbles in terms of the Jorgensonian cost of capital, which is defined as the right side of equation (18). When $n(B-1)$ is zero, that is, when there is no bubble, or when there is a bubble but the firm does not issue, we have the familiar optimality condition for capital which sets the expected marginal profitability of capital equal to its user cost. That is, $E\left[\Pi_{k}\right]=r+\delta$.

If, however, the bubble is positive and the firm actively exploits the bubble by issuing shares, then this has the effect of reducing the cost of capital. Assume $r=$ 0.10 and $\delta=0.10$, so that in the absence of bubbles, the baseline cost of capital is $20 \%$. Consider again the numerical example illustrated in figure 1. Here, the level of dispersion is $\sigma=0.5$, which causes an equilibrium bubble of $B=1.4$, and optimal equity issuance of $n=0.14$. Then according to equation (18), the bubble reduces the Jorgensonian cost of capital from $20 \%$ to $14.2 \%$. This distortion depends not only on the size of the bubble but also on the size of new share issues. To see this, reduce the value of $\gamma$ by half (to $\gamma=0.5$ ). The magnitude of bubble is identical $(B=1.4$ ), but now it is optimal for the firm to issue only half as much equity issue as it issued before ( $n=0.07$ instead of $n=0.14$ ). For the same size bubble, the distortion is smaller; the Jorgensonian cost of capital is reduced from $20 \%$ to $17.0 \%$. In short, as shown in equation (18) and illustrated in this example, the magnitude of the bubble is not sufficient to reveal the distortion of the cost of capital. Firms with small $\gamma$ have little incentive to issue new shares. For such firms, large bubbles could theoretically 
persist in equilibrium while having only a small impact on the cost of capital.

Finally, we consider the effect of dispersion on investment. In the more general case of non-zero adjustment costs for investment, equation (18) can be written:

$$
\frac{E\left(\Pi_{k}\right)+1-\delta}{1+\psi K}=\frac{1+r}{1+n(B-1)} .
$$

Assuming that the expected marginal profit of capital, $E\left(\Pi_{k}\right)$, is weakly decreasing in $K$, it follows immediately that the right side of this equation is monotonically decreasing in $K$. Since an increase in dispersion causes the equilibrium values of $B$ and $n$ to increase, this leads to a rise in investment.

\subsection{Tobin's Q}

We now consider the relation between dispersion, investment and Tobin's $Q$ in equilibrium. This analysis is important because previous empirical work on bubbles and real investment relies on the $\mathrm{Q}$ framework to control for investment opportunities. This can lead to misleading inference because Tobin's Q is itself a function of the bubble. ${ }^{18}$ Our model can be used to illustrate this point explicitly.

Tobin's Q is defined as the ratio of the market value of equity to the replacement value of capital. In our model, this translates to:

$$
Q \equiv \frac{1}{1+r}\left[\frac{B V}{K}\right]
$$

Following Hayashi (1982), we assume profits are homogenous of degree one, or $\Pi(K, \theta)=$ $\theta K$. It follows that $V_{k}=V / K=\theta+1-\delta$. In this case, according to equation (20), $Q$ depends positively on $\sigma$ through $B$. In other words, the value of Tobin's Q reflects not just shocks to investment opportunities, but also the bubble itself.

The relationship between investment and Tobin's Q can be derived by combining

\footnotetext{
${ }^{18}$ We are grateful to Andy Abel for particularly useful comments on this point.
} 
the first-order condition for investment (equation (17)), the definition of Tobin's Q (equation (20)), and our assumption of linear homogeneity. This yields:

$$
1+\psi K=\frac{1+n(B-1)}{B} Q
$$

This equation is the familiar $\mathrm{Q}$ equation, but with a new term, $[1+n(B-1)] / B$, which depends negatively on dispersion. In an investment regression that conditions on Tobin's Q, a proxy for bubbles would pick up the variation due to the term $[1+n(B-1)] / B$. This coefficient is theoretically negative, which would misleadingly suggest that higher bubbles cause lower investment.

To summarize the results in this section, heterogeneous beliefs and short-selling constraints can generate bubbles. When the distribution of investor valuations is lognormal, increases in dispersion increase both the size of the bubble and the amount of new equity issued. This lowers the cost of capital and therefore stimulates investment. The bubble alone is not sufficient for determining the magnitude of this distortion. Rather, it is the interaction between the bubble and the fraction of new equity issued that matters. Finally, we show that the equilibrium value of Tobin's $Q$ is increasing in not only the rate of investment but also in the size of the bubble. Thus, our results provide support for the common practice of using Tobin's Q (or market-to-book ratios) as indirect measures of stock price bubbles. By the same logic, our model cautions against using Tobin's Q as a proxy for investment opportunities when testing for the effects of bubbles on real investment.

\section{Empirical Analysis}

To evaluate the empirical predictions of the model we focus on the predicted causal relation running from our proxy for the dispersion of beliefs to investment, Tobin's Q, and net equity issuance. We first compare trends in dispersion, new equity issues, To- 
bin's Q and investment over the period 1986-2000. ${ }^{19}$ We divide firms into those listed on the New York Stock Exchange versus Nasdaq, because the stock price movements of the latter are commonly thought to have been driven by bubbles (more so than the former). We then consider a more detailed analysis of the data at the firm-level where we can more easily control for firms' investment opportunities.

The discussion in the previous section highlights the difficult identification issues presented by the Q framework. Specifically, because net equity issuance, Tobin's Q, and real investment all respond endogenously to dispersion, one cannot econometrically identify the existence or magnitude of bubbles by regressing real investment on Tobin's Q and new share issues. Our empirical strategy addresses this identification problem by pursuing two ideas. First, we use the variance of analysts' earnings forecast to proxy for the dispersion of investor opinion about a firm's stock value. This variable is an ideal proxy because according our model, it solely determines the magnitude of the bubble in equilibrium. It is furthermore desirable because in contrast to bubble proxies used in previous research (e.g., equity issues or lagged stock returns), there is no obvious reason why dispersion should be correlated with investment opportunities. Second, in our firm-level analysis, we use recursively ordered VARs to further isolate and identify the exogenous component of this variable. This approach is a (minimally) structural attempt to improve identification.

We assemble annual, firm-level data from two sources. First, we use Compustat to construct both aggregate and firm-level measures of the rate of investment, $I_{t} / K_{t}$, net new equity issuance as a fraction of total equity, neq $q_{t}$, Tobin's $\mathrm{Q}$ ratio, $Q_{t}$, and the marginal product of capital, $m p k_{t}$. The appendix provides more complete details on the construction of these variables.

Second, we use data on analysts' earnings forecasts available from IBES to construct aggregate and firm-level measures of the dispersion of investor opinion. Diether, Malloy and Scherbina (2002) show that historical IBES data suffer from measurement

\footnotetext{
${ }^{19}$ This time frame is set by data availability.
} 
errors induced by the truncation of significant digits. To fix this problem, they collect original source data from IBES, which they graciously shared with us. Unfortunately, these data do not extend beyond the year 2000. Therefore, to maximize the length of our time series, we use the standard IBES data in our aggregate analysis (these data extend through 2002). At the firm level, however, we use the bias-free IBES data because the added time dimension is not as critical, whereas the bias identified by Diether et al.. is potentially severe.

At the firm level, our annual proxy for dispersion exploits all of the forecasts issued by analysts over the year. We define dispersion as the logarithm of the fiscal year average of the monthly standard deviation of analysts' forecasts of earnings per share, times the number of shares, scaled by the book value of total assets. That is,

$$
d_{t}=\log \left(\frac{\sum_{j=1}^{12} N_{t-j} S D_{t-j} / 12}{\text { Total Assets }}\right) \text {, }
$$

where $N_{t-j}$ is the number of shares outstanding, and $S D_{t-j}$ is the standard deviation of the per-share earnings forecasts for all analysts making forecasts for month $j$ (we use the value of $S D_{t}$ as reported on the IBES summary tape).

Finally, to reduce the effect of outliers, we set the variables $I_{t} / K_{t}, Q_{t}, d_{t}$, and $m p k_{t}$ to missing if their values are below zero or higher than their 99th percentile; $n e q_{t}$ is trimmed at the 1st and 99th percentiles. We drop observations for which the lag between consecutive fiscal-year-ends is not exactly 12 months. In total, our firm-

level sample contains 22522 non-missing firm-year observations, of which 18421 have non-missing values for the first two lags, too. Our aggregate variables are constructed by taking equal-weighted averages of the firm-level data.

\subsection{The 1990's boom: Nasdaq versus NYSE}

Figure 3 plots the time-series averages of dispersion, Tobin's Q, the sales to capital ratio (a measure of MPK), the investment rate and net equity issuance for the sub- 
samples of firms listed on Nasdaq versus NYSE over the period 1990-2002. ${ }^{20}$ For comparison's sake, we also plot the Nasdaq versus NYSE stock price indices as well.

Nasdaq firms experienced a steady increase in dispersion relative to NYSE firms over the period 1990-2001, followed by a slight decline in $2002 .{ }^{21}$ Nasdaq firms experienced a steady increase in their investment rate relative to NYSE firms over most of this period. Nasdaq firms also show a relatively sharp increase in both Tobin's Q and net equity issuance during the later part of the boom. This sharp increase coincides with a rise in the growth rate of dispersion for the 1998-2001 period. Although timing between these variables is not exact, the latter part of the 1990's is characterized by sharp increases in dispersion, Tobin's Q, net equity issuance, and investment for Nasdaq firms relative to NYSE firms. These patterns are broadly consistent with our model's predictions.

The divergence in investment rates between Nasdaq and NYSE firms is difficult to explain based on investment fundamentals alone (as measured by the sales to capital ratio). In fact, during the early sample period, there is little difference between the marginal product of capital for NYSE versus Nasdaq firms. Then in 1999, MPK for Nasdaq firms begins to collapse while dispersion, Tobin's Q, new equity issuance, and investment all continue to rise. This is all consistent with the bubble view. To provide additional insight we now consider an empirical analysis based on the microeconometric data.

\footnotetext{
${ }^{20}$ With the exception of the net-equity issuance, we report the mean of the log of all variables for each sub-sample. For all variables, we trim outliers using a $1 \%$ cutoff rule applied to the combined NYSE and Nasdaq sample.

${ }^{21}$ Because of reporting issues with IBES vs Compustat, we lose approximately $20 \%$ of our observations in the last year of the sample. Thus the mean dispersion estimates for 2002 may not be entirely representative. Consistent with the idea that increases in dispersion contributed to the stock market boom, using medians rather than means, we see a sharper reduction in dispersion in the last year of our sample.
} 


\subsection{Panel Data VAR Analysis}

We start with a three-variable VAR system, estimated in logs, that includes the marginal product of capital, dispersion and investment. To allow for the possibility that dispersion may contain information about current investment opportunities, we consider the effect of an innovation to dispersion that is uncorrelated with the innovation to MPK. ${ }^{22}$ Hence, when computing impulse responses, we use a Choleski decomposition using the ordering $m p k_{t}, d_{t}, I_{t} / K_{t} \cdot{ }^{23}$

Table 1 reports the coefficient values of this three-variable VAR system. Table 1 also reports the t-statistics for the coefficients. ${ }^{24}$ Consistent with a key implication of our model, we observe a statistically significant positive link between dispersion and investment, controlling for the marginal product of capital. The marginal product of capital is also highly significant in the investment equation, as we would expect. We also see a positive relation between dispersion and $m p k$, a finding which suggests that our orthogonalization scheme will be helpful when identifying increases in dispersion that are not related to fundamentals.

Figure 4 reports the impulse response functions from this three-variable VAR. We report the effects of shocks to $m p k_{t}$ which we interpret as a shock to the fundamental investment opportunities of the firm, and we report the effects of a shock to dispersion,

\footnotetext{
${ }^{22}$ Dispersion would contain information about investment opportunities if shocks to fundamentals trigger disagreement among analysts.

${ }^{23}$ Formally, we estimate the model $\mathbf{y}_{i t}=\mathbf{A y}_{i t-1}+\mathbf{f}_{i}+\mathbf{e}_{t}+\mathbf{v}_{i t}$, where $\mathbf{y}_{i t}=\left\{m p k_{i t}, d_{i t}, I_{i t} / K_{i t}\right\}^{\prime}$, $\mathbf{A}$ is a $3 \times 3$ matrix of coefficients, $\mathbf{f}_{i}$ is a vector of fixed firm effects, and $\mathbf{e}_{t}$ is a vector of common time shocks. We estimate the model following the procedure described in Arellano and Bover (1995). Our ordering for the three-variable case implies that the vector of residuals $\mathbf{v}_{i t}$ is related to a set of mutually orthogonal structural shocks $\eta_{i t}=\left\{\eta_{i t}^{m p k}, \eta_{i t}^{d}, \eta_{i t}^{I / K}\right\}^{\prime}$ according to the following recursive
} structure:

$$
\begin{aligned}
v_{i t}^{m p k} & =\eta_{i t}^{m p k} \\
v_{i t}^{d} & =\rho_{i q} \eta_{i t}^{m p k}+\eta_{i t}^{d} \\
v_{i t}^{I / K} & =\rho_{d q} \eta_{i t}^{m p k}+\rho_{d i} \eta_{j t}^{d}+\eta_{j t}^{I / K} .
\end{aligned}
$$

${ }^{24}$ We do not report $R^{2}$ statistics because we estimate the model using instrumental variables. 
which, within the context of our model leads to an increase in the bubble (price relative to fundamentals).

The effect of a one-standard deviation shock to $m p k_{t}$ is reported in the first row of Figure 4. The immediate effect of the shock is to increase both $m p k_{t}$ and investment by approximately the same magnitude (0.2), following which both variables return to steady-state at approximately the same rate. This finding implies a unit elasticity between investment and the marginal product of capital following a shock to fundamentals.

The effect of a one standard deviation shock to dispersion is reported in the second row of Figure 4. Consistent with our model, an innovation to dispersion leads to a pronounced increase in investment. The peak response of investment is on the order of 0.1 percent and occurs in the year following the shock. The increase in dispersion also causes a rise in $m p k_{t}$ but the magnitude is relatively small. Using unit elasticity as a reasonable measure of how investment should respond to fundamentals, most of the increase in investment following a shock to dispersion can be attributed to changes in dispersion that are orthogonal to future $m p k{ }^{25}$

To examine the empirical link between dispersion, Tobin's Q and net equity issuance, we add these variables to the baseline VAR. For parsimony, we focus on the impulse response functions rather than coefficient values. ${ }^{26}$ We again consider innovations based on a Cholesky decomposition using the following ordering: $\left[m p k_{t}, d_{t}, I / K_{t}, Q_{t}, n e q_{t}\right]$. The results are reported in Figure 5.

\footnotetext{
${ }^{25}$ If we interpret approximately unit elasticity response of of investment to the innovation in $m p k$ as providing a reasonable measure of how investment responds to fundamentals, then we would attribute $1 / 3$ (0.03 out of 0.1 ) of the rise in investment to fundamentals following a shock to dispersion. The remaining $2 / 3$ response ( 0.07 out of 0.1 ) would be attributable to movements in dispersion not linked to fundamentals.

${ }^{26}$ Our model suggests that in a regression of investment on Tobin's Q and dispersion, we should find a negative effect of dispersion on investment. Adding Tobin's $Q$ to the investment equation reduces the coefficient on dispersion but they remain positive. Because such regressions do not control for the contemporaneous correlations however, we do not necessarily interpret this as a rejection of the model. Rather, it highlights the need for additional identification through the choleski decomposition.
} 
The impulse response to a one standard deviation shock to $m p k_{t}$ is reported in the first row of Figure 5. Adding the additional variables does not change the basic relation between fundamentals and investment that we observed in Figure 4. A shock to $m p k_{t}$ leads to a modest rise in Tobin's Q and a small increase in equity issuance upon impact of the shock. Both of these responses are consistent with the notion that Tobin's Q and equity issuance respond endogenously to fundamental investment opportunities.

The response of investment and fundamentals to an innovation in dispersion is also similar to the results obtained using the three-variable VAR system albeit slightly weaker. Investment responds with some lag and shows a peak response on the order of 0.08 . The increase in $m p k_{t}$ is again positive but relatively small in magnitude - on the order of 0.04. Again, using unit elasticity as a benchmark, this finding suggests that slightly less than half of the response of investment to the dispersion shock can be explained by the response of fundamentals, the other half is attributable to a non-fundamental component and is therefore consistent with the notion that bubbles drive investment.

The innovation to dispersion leads to an increase in Tobin's $Q$ and a rise in equity issuance - both of these responses are consistent with the model's predictions. They are also large in magnitude relative to the investment response. Following a shock to $m p k_{t}$, the peak increase in Tobin's $\mathrm{Q}$ is one third the size of the peak increase in investment. In contrast, following a shock to dispersion, the peak increase in Tobin's $\mathrm{Q}$ is nearly the same size as the increase in investment. Our model implies that in the absence of bubbles, investment is a sufficient statistic for Tobin's Q regardless of the source of the shock. In the presence of bubbles, Tobin's Q should reflect both the increase in investment and the increase in the bubble however (see equation (21)). This additional impact on $\mathrm{Q}$ through the bubble, controlling for investment implies that $Q_{t}$ should respond more to dispersion shocks, controlling for investment. Our model thus rationalizes the finding that $\Delta \ln Q_{t} / \Delta \ln \left(I_{t} / K_{t}\right)$ is larger in response to 
shocks to dispersion relative to shocks to $m p k_{t}$.

In both the three-variable and the five-variable VAR results, innovations in dispersion cause increases in investment, Tobin's Q, and net equity issuance that are consistent with our model predictions. Identification is complicated by the tendency of $m p k_{t}$ to respond positively to increases in dispersion, but the response is relatively weak, suggesting that most of the movement in investment, Q and net equity issuance following a shock to dispersion can be attributed to non-fundamental components, i.e. bubbles.

Although not reported, we also consider the effects of a shock to Tobin's Q that is orthogonal to $m p k_{t}$ and dispersion. Such a shock also causes an increase in Tobin's $\mathrm{Q}$, investment, and net equity issuance, but a pronounced fall in $m p k_{t}$. The drop in $m p k_{t}$ is inconsistent with the view that these impulse responses reflect a rise in fundamentals. It is, however, consistent with the view that the orthogonalized shock to Tobin's Q reflect a reduction in the cost of capital. Such variation in Tobin's Q may reflect time-variation in covariance risk, or it may reflect movements in bubbles not driven by dispersion.

To assess the quantitative importance of these results, we compute a variance decomposition of the five-variable VAR based on the above ordering. We report results at the 10-year horizon; similar results are obtained at shorter horizons. Because we control for time dummies and fixed effects in our panel-data framework, these variance decompositions provide information about the within-firm variation only, and hence cannot be used to quantify the importance of bubbles in the aggregate.

Table 2 reveals that most of the variation in each variable is determined by its own shock. The exception is investment, for which fundamentals play the dominant role. Dispersion explains only a small fraction of the total variance of investment. When compared to the fraction explained by Tobin's Q (7.5 percent), this number is reasonably large however. Dispersion also explains 1.5 percent of the variation in $m p k$ and Tobin's Q. Interestingly, dispersion accounts for more of the variance of net 
equity issuance (6 percent) than any other variable besides net equity issuance itself. In the absence of mispricing, the firm is indifferent between equity issuance and other forms of finance. It is therefore perhaps not surprising that dispersion would account for a reasonable fraction of the variation in share issuance.

The variance decompositions suggest that dispersion only accounts for a small fraction of investment. This finding is not surprising for several reasons. First, as mentioned above, our panel data estimates do not identify the macro variation in the bubble component. ${ }^{27}$ Second, analysts are reasonably informed agents. Dispersion in analysts forecasts is therefore likely to understate the true amount of disagreement in the market place. Finally, the model itself implies that the effect of bubbles on investment will be limited, since the firm is unwilling to fully exploit the bubble in equilibrium.

\section{Conclusion}

Building on Miller (1977) and Chen, Hong and Stein (2002), we develop a model in which increases in dispersion of investor opinion cause stock prices to rise above their fundamental values. We consider the optimal share issuance and investment decisions of rational managers in response to such mispricing. Our model predicts that an increase in dispersion causes increases in Tobin's Q, net new share issues, and real investment. We test these predictions using the variance of analysts' earnings forecasts to proxy for shocks to the dispersion of investor beliefs. This proxy effectively allows us to identify a portion of the bubble component in Tobin's Q. Using a recursive ordering of a panel data VAR for identification, we find that shocks to dispersion have positive and statistically significant effects on Tobin's Q, net equity issuance, and real investment. These results confirm the model's key predictions.

\footnotetext{
${ }^{27}$ Our aggregate plots, though anecdotal, suggest that the distortion caused by dispersion could be more substantial than our panel data estimates suggest.
} 
Substantial room for future research remains. It would be desirable to extend our model to allow for the endogenous formation of beliefs (as in Scheinkman and Xiong, 2003, for example). Extending our model to include debt issuance may help explain the capital structure dynamics documented in Baker and Wurgler (2003). Finally, adding investment dynamics would provide a more suitable structural framework for quantifying the real effects of bubbles. 


\section{Bibliography}

Allen, F., S. Morris, and H.S. Shin, 2003, "Beauty contests and iterated expectations in asset markets," Working Paper, Yale University.

Arellano, M. and O. Bover, 1995, "Another look at the instrumental variable estimation of error component models," Journal of Econometrics 68, 29-51.

Asquith, P. and D.W. Mullins, 1986, "Equity issues and offering dilution," Journal of Financial Economics 15, 61-89.

Baker, M., J. Stein, and J. Wurgler, 2003, "When does the market matter? Stock prices and the investment of equity dependent firms," Quarterly Journal of Economics 118, 969-1006.

Baker, M. and J. Wurgler, 2002, Market timing and capital structure, Journal of Finance 57, 1-32.

Bertrand, M. and A. Schoar, 2002, "Managing with style: The effect of managers on firm policies," Working Paper, MIT.

Blanchard, O.J., C. Rhee, and L. Summers, 1993, "The stock market, profit and investment," Quarterly Journal of Economics 108, 115-136.

Bond, S.R. and J.G. Cummins, 2000, "Noisy share prices and the q model of investment," Working Paper No. W01/22, Institute for Fiscal Studies, London.

Chen, J., H. Hong, and J.C. Stein, 2002, "Breadth of ownership and stock returns," Journal of Financial Economics 66, 171-205.

Chirinko, R.S., 1996, "Bubbles, fundamentals, and investment: A multiple equation testing strategy," Journal of Monetary Economics 38, 47-76.

Chirinko, R.S. and H. Schaller, 2001, "Business fixed investment and 'bubbles': The Japanese case," American Economic Review 91, 663-680.

Diether, K.B., C.J. Malloy, and A. Scherbina, 2002, "Differences of opinion and the cross-section of stocks returns," Journal of Finance 57, 2113-2141.

D'Avolio, G.D., 2002, "The market for borrowing stock," Journal of Financial Economics 66, 271-306.

Duffie, D., N. Garleanu and L. Pedersen, 2001, "Securities lending, shorting, and pricing," Journal of Financial Economics 66, 307-339.

Erickson, T. and T. Whited, 1999, "Measurement error and the relation between investment and q," Journal of Political Economy 108, 1027-1057. 
Gilchrist, S., and C.P. Himmelberg, 1998, "Investment, Fundamentals, and Finance," In B. Bernanke and J.J. Rotemberg, eds., NBER Macroeconomics Annual (MIT Press, Cambridge).

Hayashi, F., 1982, "Tobin's marginal q and average q: A neoclassical interpretation," Econometrica 50, 213-224.

Heaton, J. B., 1999, "Managerial optimism and corporate finance," Working Paper, University of Chicago.

Hirshleifer, D., 2001, "Investor psychology and asset pricing," Journal of Finance $56,1533-1597$.

Holthausen, R., Leftwich, R. and D. Mayers, 1990, "Large block transactions, the speed of response, and temporary and permanent stock-price effects," Journal of Financial Economics 26, 71-95.

Hong, H., and J.C. Stein, 2003, "Differences of opinion, short-sales constraints and market crashes," Review of Financial Studies 16, 487-525.

Huberman, G., and T. Regev, 2001, "Contagious speculation and a cure for cancer: A non-event that made stock prices soar," Journal of Finance 56, 387-396.

Johnson, N.L., S. Kotz, and N. Balakrishnan, 1994, Continous univariate distributions, Vol. 1, Second edition (John Wiley \& Sons, New York).

Jones, C. and O. Lamont, 2002, "Short-sale constraints and stock returns," Journal of Financial Economics 66, 207-39.

Keynes, J.M., 1936, The general theory of employment, interest and money (Macmillan, London).

Lakonishok, J., A. Shleifer, and R.V. Vishny, 1994, "Contrarian investment, extrapolation and risk," Journal of Finance 49, 1541-1578.

Loderer, C., J.W. Cooney and L.D. Van Drunen, 1991, "The Price Elasticity of Demand for Common Stock", Journal of Finance 46, 621-651.

Malmendier, U., and G. Tate, 2001, "CEO overconfidence and corporate investment," Working Paper, Harvard University.

Miller, E.M., 1977, "Risk, uncertainty, and divergence of opinion," Journal of Finance $32,1151-1168$.

M $\phi$ rck, R., A. Shleifer, and R.W. Vishny, 1990, "The stock market and investment: Is the market a sideshow?" Brookings Papers on Economic Activity 0, 157-202. 
M $\phi$ rck, R., A. Shleifer, and R.W. Vishny, 1990, "Do managerial objectives drive bad acquisitions?" Journal of Finance 45, 31-48.

Ofek, E. and M. Richardson, 2003, "Dotcom mania: The rise and fall of internet stock prices," Journal of Finance 58, 1113-1137.

Panageas, Stavros, 2004, "Speculation, overpricing, and investment - theory and empirical evidence," MIT Mimeo.

Park, C., 2001, "Stock returns and the dispersion in earnings forecasts," Working Paper No. 0117, Department of Economics, National University of Singapore.

Polk, C. and P. Sapienza, 2002, "The real effects of investor sentiment," Working Paper, Northwestern University.

Scheikman, J. and W. Xiong, 2003, "Overconfidence and bubbles," The Journal of Political Economy 111, 1183-1219.

Scholes, Myron S., 1972, The market for securities: Substitution versus price pressure and the effects of information on share prices, Journal of Business 45, 179-211.

Shleifer, A., 1986, "Do demand curves for stocks slope down?" Journal of Finance $41,579-590$.

Shleifer, A., 2000, Inefficient markets: An introduction to behavioral finance (Oxford University Press, Oxford).

Shleifer, A. and R.V. Vishny, 1997, "The limits of arbitrage," Journal of Finance $52,35-55$.

Stein, J.C., 1996, "Rational capital budgeting in an irrational world," Journal of Business 69, 429-455. 


\section{A Appendix: Model Results}

\section{A.1 Properties of the Inverse Demand Curve}

We first use equation 4 combined with equation 3 to establish the limiting behavior of the demand curve. We then compute and sign the derivatives $B_{n}$ and $B_{\sigma}$. It is easier to work with the following version of equation 4

$$
n^{d}(B, \sigma)=\gamma\left[(1-\Phi(b-\sigma)) B^{-1}-(1-\Phi(b))\right] .
$$

Since $\lim _{B \rightarrow 0} b=-\infty$ and $\lim _{B \rightarrow \infty} b=\infty$

$$
\lim _{B \rightarrow 0} \gamma\left[(1-\Phi(b-\sigma)) B^{-1}-(1-\Phi(b))\right]=\lim _{B \rightarrow 0} \gamma B^{-1}=\infty
$$

To compute the upper limit, we note that $\frac{\partial b}{\partial B}=\frac{1}{\sigma B}$ and apply l'Hopital's rule to obtain

$$
\lim _{B \rightarrow \infty} \gamma\left[(1-\Phi(b-\sigma)) B^{-1}-(1-\Phi(b))\right]=\lim _{B \rightarrow \infty}-\gamma \frac{\phi(b-\sigma)}{\sigma B}=0 .
$$

Thus we have that $\lim _{B \rightarrow 0} n^{d}(B, \sigma)=\infty$ and $\lim _{B \rightarrow \infty} n^{d}(B, \sigma)=0$. We now compute the partial derivative of $n$ with respect to $B$, recognizing that $b$ is a function of $B$ :

$$
\frac{\partial n}{\partial B}=\gamma\left[-\left[\phi(b-\sigma) B^{-1}-\phi(b)\right] \frac{\partial b}{\partial B}-[1-\Phi(b-\sigma)] \frac{1}{B^{2}}\right] .
$$

By the properties of the lognormal, $\phi(b-\sigma)=\phi(b) B$. Hence the first term in this expression is zero, so that

$$
\frac{\partial n}{\partial B}=-\gamma[1-\Phi(b-\sigma)] B^{-2}<0 .
$$

The limiting conditions in equations 23 and 24 and the derivative in equation 25 establish that the market demand curve in equation 4 is invertible with

$$
B_{n}=\frac{-B^{2}}{\gamma[1-\Phi(b-\sigma)]}<0 .
$$

To compute $B_{\sigma}=\frac{\partial B}{\partial \sigma}$, we totally differentiate equation (22), holding $n$ fixed:

$$
\begin{aligned}
0 & \left.=\gamma\left[-\left(\phi(b-\sigma) B^{-1}-\phi(b)\right) \frac{\partial b}{\partial \sigma}+\phi(b-\sigma)\right) \frac{1}{B}\right] \partial \sigma+\frac{\partial n}{\partial B} \partial B \\
& =\gamma \frac{\phi(b-\sigma)}{B} \partial \sigma+\frac{\partial n}{\partial B} \partial B .
\end{aligned}
$$


Solving for $\frac{\partial B}{\partial \sigma}$ we obtain:

$$
B_{\sigma}=-\gamma \phi(b) B_{n} .
$$

Substituting in our expression for $B_{n}$, we obtain

$$
B_{\sigma}=B h(b-\sigma)>0 .
$$

\section{A.2 Derivation of the Equilbrium Price}

To show that a unique solution to equation 12 exists, we use equation 3 to express equation 12 as an equation in $b$ :

$$
\exp \left(\sigma b-0.5 \sigma^{2}\right)=\frac{h(b)}{h(b-\sigma)}
$$

The left-hand-side of this equation is strictly positive and monotonically increasing in $b$. The hazard rate for the standard normal $h(b)$ is monotonically increasing so that $\frac{h(b)}{h(b-\sigma)}>1$. It is also straightforward to show that $\lim _{b \rightarrow-\infty} \frac{h(b)}{h(b-\sigma)}=\infty$, $\lim _{b \rightarrow-\infty} \frac{h(b)}{h(b-\sigma)}=0$ The derivative of the right-hand-side of equation 12 satisfies

$$
\begin{aligned}
\frac{\partial}{\partial b}\left(\frac{h(b)}{h(b-\sigma)}\right) & =\frac{h(b)}{h(b-\sigma)}\left(\frac{h^{\prime}(b)}{h(b)}-\frac{h^{\prime}(b-\sigma)}{h(b-\sigma)}\right) \\
& =\frac{h(b)}{h(b-\sigma)}(h(b)-h(b-\sigma)-\sigma)<0,
\end{aligned}
$$

Log-concavity of $h(x)$ implies that $(h(b)-h(b-\sigma)-\sigma)<0$ which establishes the inequality (see the appendix of Gilchrist and Williams, 2001). These results are sufficient to guarantee a unique equilibrium value of $b$ and hence $B$ for equation 12. The uniqueness of the equilibrium value $n(\sigma, \gamma)$ for equity issuance, equation 13 , follows directly from these results.

\section{A.3 The Effect of an Increase in Dispersion on Price and Equity Issuance}

Before analyzing the equilibrium response of $B$ and $n$ to an increase in dispersion, we first establish that equilibrium occurs at $b>\sigma$. To do so we note that at $b=\sigma$ we have

$$
\begin{gathered}
\frac{h(b)}{h(b-\sigma)}-\left.B\right|_{b=\sigma}=\exp \left(-0.5 \sigma^{2}\right)\left[\frac{\exp \left(0.5 \sigma^{2}\right)}{2(1-\Phi(\sigma))}-1\right] \\
>0 \text { for } \sigma>0 .
\end{gathered}
$$


To obtain the inequality, we note that at $\sigma=0$, the term in brackets on the right-handside of this expression is identically zero. This term is also strictly increasing in $\sigma$ and therefore positive for $\sigma>0$. Thus at $b=\sigma$ we have $\frac{h(b)}{h(b-\sigma)}>B$. Since $h(b) / h(b-\sigma)$ is decreasing in $b$ and $B=\exp \left(\frac{b-0.5 \sigma^{2}}{\sigma}\right)$ is increasing in $b$, the equilibrium must therefore occur at $b>\sigma$.

We now totally differentiate equation (12) to obtain $\frac{d B}{d \sigma}$. For short-hand notation, let $g(B, \sigma)=h(b) / h(b-\sigma)$ so that equilibrium implies $B=g$. It is straightforward to show that

$$
\frac{d B}{d \sigma}=\frac{\left[g_{b} \frac{\partial b}{\partial \sigma}+g_{\sigma}\right]}{\left[1-g_{b} \frac{\partial b}{\partial B}\right]} .
$$

where

$$
\begin{aligned}
g_{b} & =g[h(b)-h(b-\sigma)-\sigma]<0 \\
g_{\sigma} & =g[h(b-\sigma)-(b-\sigma)]>0
\end{aligned}
$$

and

$$
\begin{aligned}
& \frac{\partial b}{\partial \sigma}=\frac{-(b-\sigma)}{\sigma} \\
& \frac{\partial b}{\partial B}=\frac{1}{B \sigma} .
\end{aligned}
$$

Inserting these expressions and simplifying, we obtain

$$
\begin{aligned}
\frac{d B}{d \sigma} & =\frac{\left[\frac{-(b-\sigma)}{\sigma} g[h(b)-h(b-\sigma)-\sigma]+g[h(b-\sigma)-(b-\sigma)]\right]}{\left[1-g[h(b)-h(b-\sigma)-\sigma] \frac{1}{B \sigma}\right]} \\
& =\frac{B[-(b-\sigma)[h(b)-b-(h(b-\sigma)-(b-\sigma)]+\sigma[h(b-\sigma)-(b-\sigma)]]}{[\sigma-[h(b)-h(b-\sigma)-\sigma]]} .
\end{aligned}
$$

Simplifying we have:

$$
\frac{d B}{d \sigma}=\frac{B(b[h(b-\sigma)+\sigma-h(b))]+\sigma[h(b)-b])}{(\sigma+[h(b-\sigma)+\sigma-h(b)])}>0 .
$$

Again, log-concavity of the hazard rate implies that $h(b-\sigma)+\sigma-h(b)>0$ so that all the terms in square brackets in equation 26 are positive which establishes the inequality. 
To show $\frac{d B / B}{d \sigma}<h(b-\sigma)$ we note that $\left[1-g_{b} \frac{\partial b}{\partial B}\right]>1$ so that

$$
\begin{aligned}
\frac{d B / B}{d \sigma} & =\frac{\left[\frac{g_{b}}{g} \frac{\partial b}{\partial \sigma}+\frac{g_{\sigma}}{g}\right]}{\left[1-g_{b} \frac{\partial b}{\partial B}\right]} \\
& <\frac{g_{b}}{g} \frac{\partial b}{\partial \sigma}+\frac{g_{\sigma}}{g}
\end{aligned}
$$

where

$$
\begin{aligned}
\frac{g_{b}}{g} \frac{\partial b}{\partial \sigma}+\frac{g_{\sigma}}{g} & =[h(b-\sigma)-h(b)+\sigma]\left(\frac{b-\sigma}{\sigma}\right)+[h(b-\sigma)-(b-\sigma)] \\
& =h(b-\sigma)-[h(b)-h(b-\sigma)]\left(\frac{b-\sigma}{\sigma}\right)
\end{aligned}
$$

As established above, equilibrium requires $b>\sigma$. The term in brackets is positive implying,

$$
\frac{g_{b}}{g} \frac{\partial b}{\partial \sigma}+\frac{g_{\sigma}}{g}<h(b-\sigma)
$$

therefore

$$
\frac{d B / B}{d \sigma}<h(b-\sigma)
$$

To compute $\frac{d n}{d \sigma}$, we use equation 22 and equation 12 to provide an alternative expression for equity issuance in equilibrium:

$$
n=\gamma\left[(1-\Phi(b-\sigma)) B^{-1}-(1-\Phi(b))\right] .
$$

Totally differentiating equation 27 with respect to $\sigma$ we obtain

$$
\frac{d n}{d \sigma}=-\gamma\left[\phi(b-\sigma) B^{-1}-\phi(b)\right] \frac{d b}{d \sigma}+\gamma(1-\Phi(b-\sigma)) B^{-2} \frac{d B}{d \sigma}+\frac{\gamma \phi(b-\sigma)}{B}
$$

The term in brackets is identically zero. Rearranging yields:

$$
\frac{d n}{d \sigma}=\gamma \frac{[(1-\Phi(b-\sigma))]}{B}\left(h(b-\sigma)-\frac{d B / B}{d \sigma}\right) .
$$

\section{B Appendix: Data construction}

We assemble annual, firm-level data from two sources. Data on sales, capital expenditures, net cash flows from equity issuance, total assets, total liabilities, preferred equity, and property, plant and equipment are obtained from Standard \& Poors Compustat. These variables are merged with a custom data extract on analysts forecasts provided by IBES to Deither, Malloy and Scherbina (2002) (and kindly provided to 
us by Anna Scherbina). In contrast to the usual IBES data, the data used in Deither et al. do not suffer from measurement errors caused by the truncation of significant digits (see their paper for further details). Variable definitions are as follows.

- Investment $\left(I_{t} / K_{t}\right)$ is the ratio of capital expenditures to beginning-of-period net book value of property, plant and equipment.

- Marginal profit of capital ( $m p k_{t}$, or "MPK") is the logarithm of a standardized ratio of sales divided by lagged book value of property, plant and equipment (end-of-fiscal-year values). Before taking logs, the sales-to-capital is divided by the industry average ratio (computed on a sample trimmed at the one percent tails), and then multiplied by 0.2 . This standardization accomodates crossindustry differences in the fixed capital share of production, and reduces the chance of misclassifying ratios in low-capital industries as "outliers." In steady state, MPK should equal the long-run cost of capital, $r+\delta$. Normalizing the scaled ratio by $r+\delta=0.2$ thus centers the sample average of MPK at a reasonable value, but obviously has no effect on the statisticaly properties of our estimates. For details, see Gilchrist and Himmelberg (1998).

- Dispersion $\left(d_{t}\right)$ is the logarithm of the fiscal year average of the monthly standard deviation of analysts' forecasts of earnings per share, times the number of shares, divided by the book value of total assets. That is,

$$
d_{t}=\log \left(\frac{\sum_{j=1}^{12} N_{t-j} \sigma_{t-j} / 12}{\text { Total Assets }}\right),
$$

where $N_{t-j}$ is the number of shares outstanding, and $S D_{t-j}$ is the standard deviation of the per-share earnings forecasts for all analysts making forecasts for month $j$ (we use the value of $S D_{t}$ as reported on the IBES summary tape). The standard deviation is computed by IBES using only those forecasts that have been recently updated.

- Net equity issuance $\left(n e q_{t}\right)$ is cash from new share issues minus cash used for share repurchases during the fiscal year divided by the beginning-of-period market value of equity (and multiplied by 100).

- Tobin's $Q,\left(Q_{t}\right)$ is the market value of equity plus the book value of preferred equity plus the book value of total liabilities divided by beginning-of-period book value of total assets.

The variables $I_{t} / K_{t}, Q_{t}, d_{t}$, and $m p k_{t}$ are set to missing if their values are below zero or higher than their 99th percentile; $n e q_{t}$ is trimmed at the 1st and 99th percentiles. Trimming reduces the impact of extreme values which are common for ratios in firm panels drawn from accounting data. The use of logs (where possible) also mitigates 
this problem. We drop observations for which the lag between consecutive fiscal-yearends is not exactly 12 months. (The month in which the fiscal years sometimes changes for such reasons as mergers or restructurings.) Our final sample size is constrained by the availability of IBES data. From 1979 through 1985, sample size rises from 54 to 95. (Excluding these early years from our sample does not change our results). In 1986, the sample size rises sharply to 1185 firms, and then increases more or less steadily to 1771 firms in year 2000. In total, our sample contains 22522 non-missing firm-year observations, of which 18421 have non-missing values for the first two lags, too. Table A reports summary statistics on the full sample.

Table A: Summary Statistics

\begin{tabular}{l|rrrrrrrr}
\hline \hline & & & & \multicolumn{5}{c}{ Percentiles } \\
\cline { 5 - 9 } Variable & & Mean & S.D. & Min & 25 th & 50 th & 75 th & Max \\
\hline $\ln m p k_{t}$ & 22522 & -1.786 & 0.712 & -6.086 & -2.181 & -1.809 & -1.426 & 3.249 \\
$\ln d_{t}$ & 22522 & 0.383 & 1.370 & -5.495 & -0.538 & 0.280 & 1.231 & 7.065 \\
$\ln \left(I_{t} / K_{t}\right)$ & 22522 & -1.341 & 0.912 & -7.131 & -1.897 & -1.365 & -0.800 & 4.922 \\
$\ln Q_{t}$ & 22522 & 0.542 & 0.585 & -1.548 & 0.154 & 0.417 & 0.836 & 4.694 \\
$\ln n e q_{t}$ & 22522 & 0.012 & 0.137 & -1.188 & -0.008 & 0.000 & 0.000 & 8.068 \\
\hline \hline
\end{tabular}

Finally, the IBES data provided by Deither et al. effectively end in 2000. To construct aggregate means through 2002, we instead use standard IBES data. Comparing overlapping data in the pre-2001 period shows that annual means are not sensitive to the truncation issues. 
Table 1

Estimates of Three-Variable VAR

\begin{tabular}{l|ccc}
\hline \hline & $\ln m p k_{t}$ & $\ln d_{t}$ & $\ln (I / K)_{t}$ \\
\hline $\ln m p k_{t-1}$ & 0.933 & 0.436 & 0.459 \\
& $(30.408)$ & $(10.920)$ & $(9.523)$ \\
$\ln m p k_{t-2}$ & -0.093 & -0.229 & -0.308 \\
& $(4.117)$ & $(7.267)$ & $(8.647)$ \\
$\ln d_{t-1}$ & 0.044 & 0.531 & 0.091 \\
& $(3.996)$ & $(27.754)$ & $(4.322)$ \\
$\ln d_{t-2}$ & 0.029 & 0.121 & 0.097 \\
& $(4.871)$ & $(10.582)$ & $(7.948)$ \\
$\ln (I / K)_{t-1}$ & -0.164 & -0.080 & 0.459 \\
& $(13.763)$ & $(4.416)$ & $(22.042)$ \\
$\ln (I / K)_{t-2}$ & 0.052 & 0.087 & 0.134 \\
& $(5.972)$ & $(6.416)$ & $(8.266)$ \\
\hline \hline
\end{tabular}

Notes: Robust t-statistics appear in parentheses.

Sample contains 18421 firm-year observations. 
Table 2

Variance Decomposition at 10-Year Horizon

\begin{tabular}{l|lllll}
\hline \hline & \multicolumn{5}{|c}{ Fraction of Total Variance Explained } \\
Shocks & $\ln m p k$ & $\ln d$ & $\ln Q$ & $\ln n e q$ & $\ln (I / K)$ \\
\hline $\ln m p k$ & 0.869 & 0.068 & 0.153 & 0.043 & 0.480 \\
$\ln d$ & 0.015 & 0.897 & 0.015 & 0.059 & 0.014 \\
$\ln Q$ & 0.002 & 0.012 & 0.727 & 0.003 & 0.075 \\
$\ln n e q$ & 0.002 & 0.000 & 0.083 & 0.884 & 0.015 \\
$\ln (I / K)$ & 0.111 & 0.023 & 0.021 & 0.010 & 0.416 \\
\hline \hline
\end{tabular}


Figure 1

Equilibrium price bubble (B) and share issuance (n)

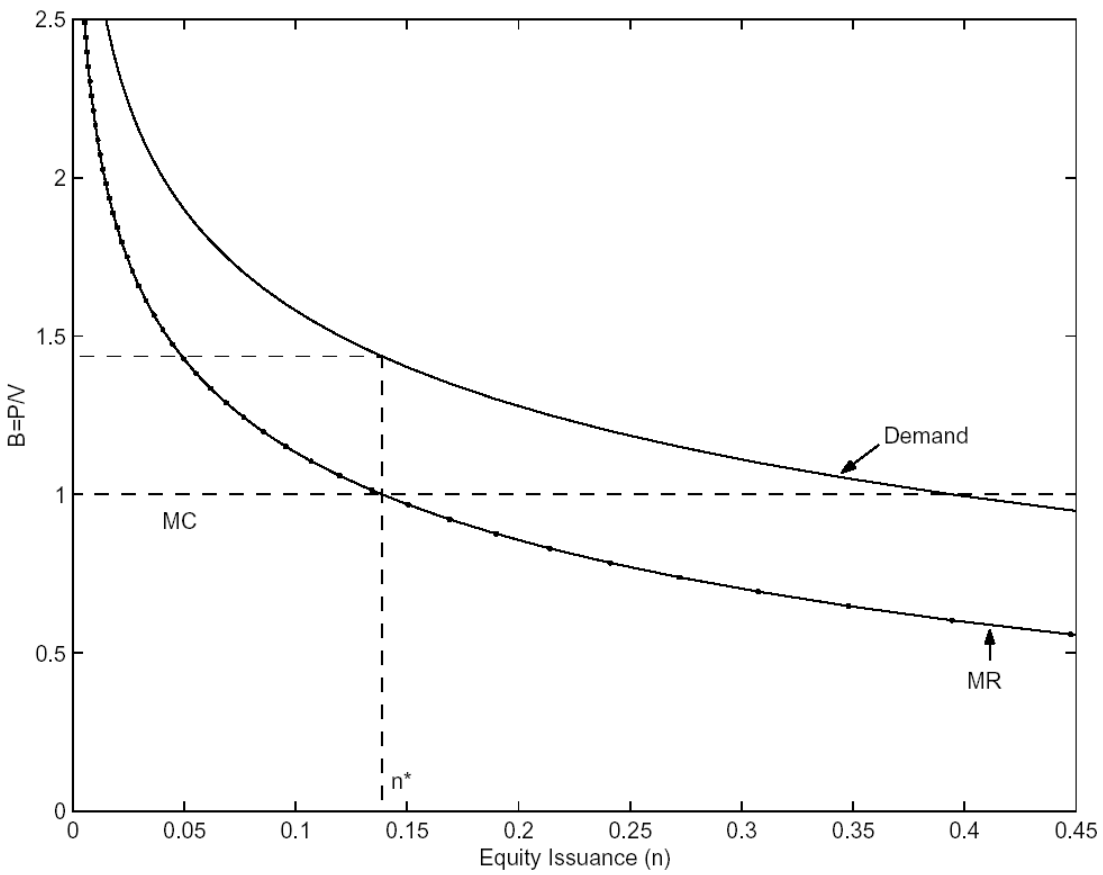

Figure 2

The effect of an increase in dispersion

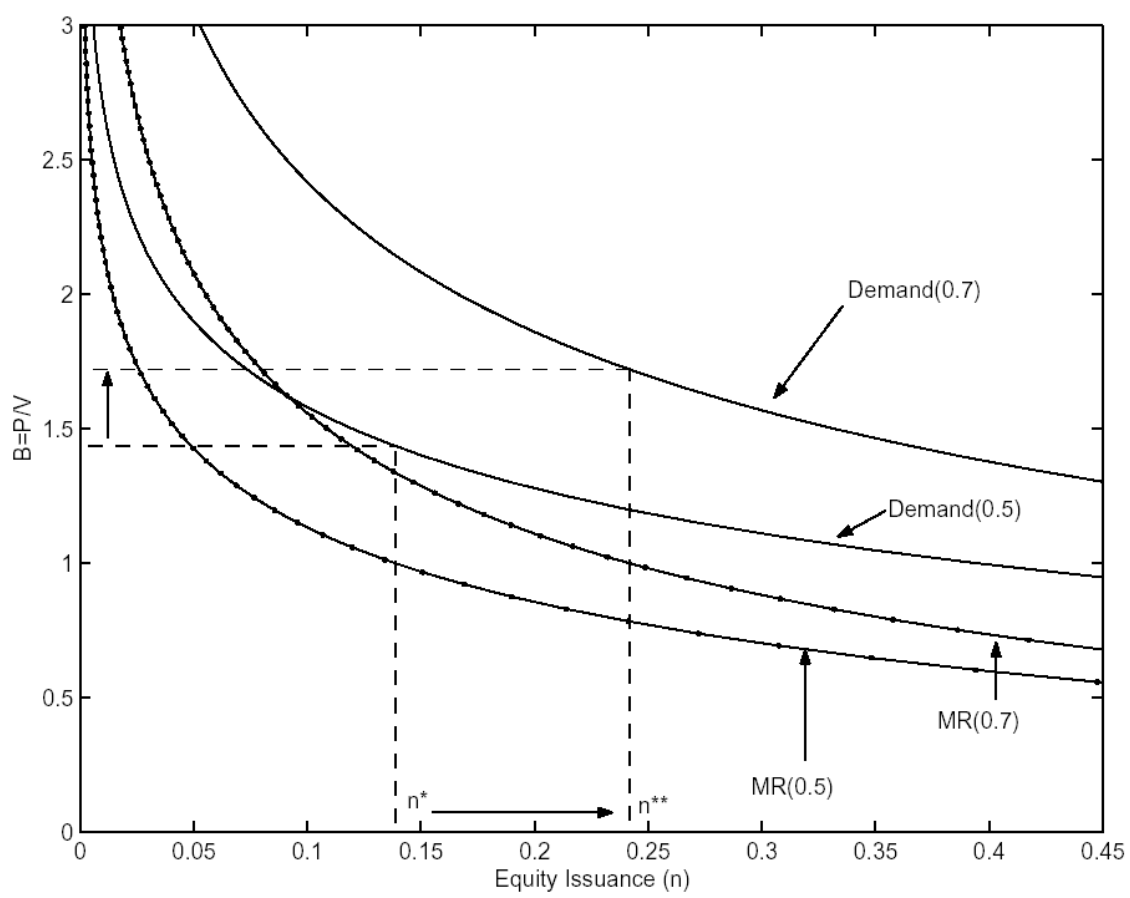




\section{Figure 3}

Comparison of Nasdaq vs. NYSE firms for the time period 1990-2002. Figure (a) plots the stock market index. Figures (b)-(f) plot the log of the (trimmed) sample means in each year, normalized to one in 1990.

a) Stock Market Index

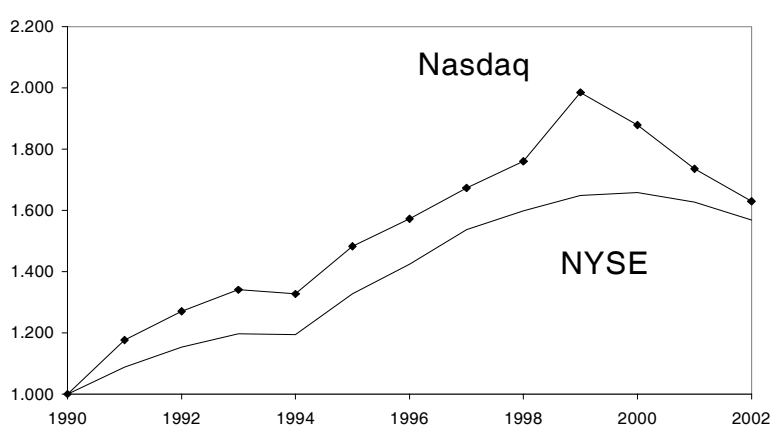

c) Mean of Log Tobin's Q

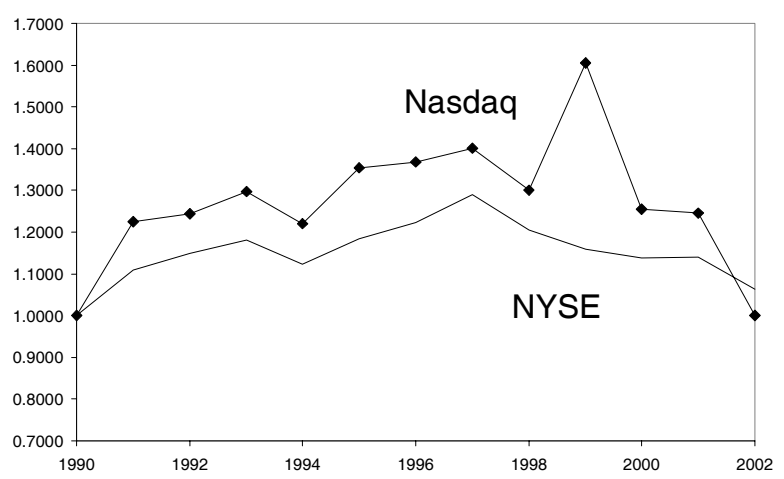

e) Mean of Net Equity Issues / Assets

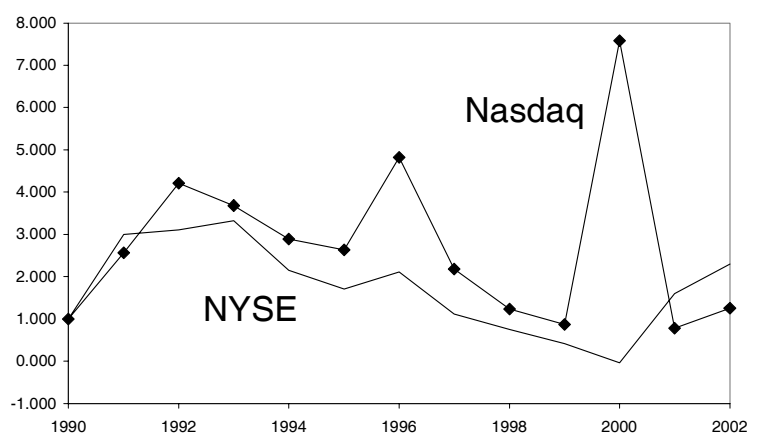

b) Mean of Log Dispersion

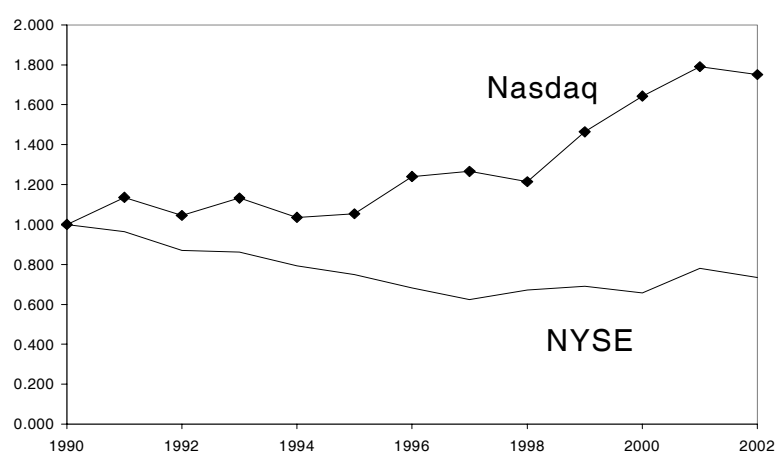

d) Mean of Log Sales / Capital

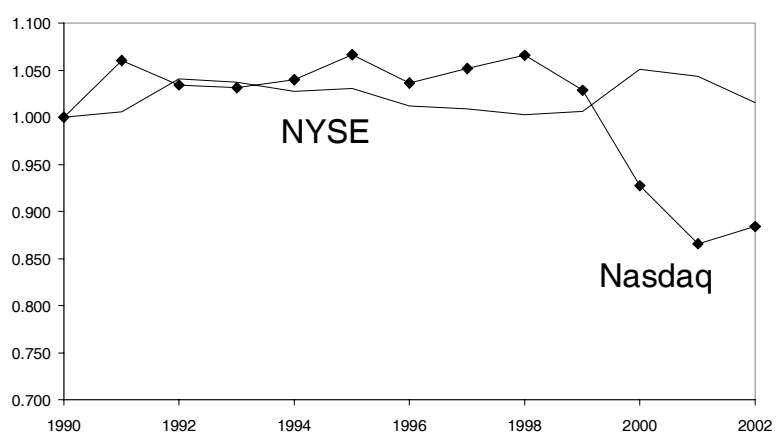

f) Mean of Log Investment / Capital

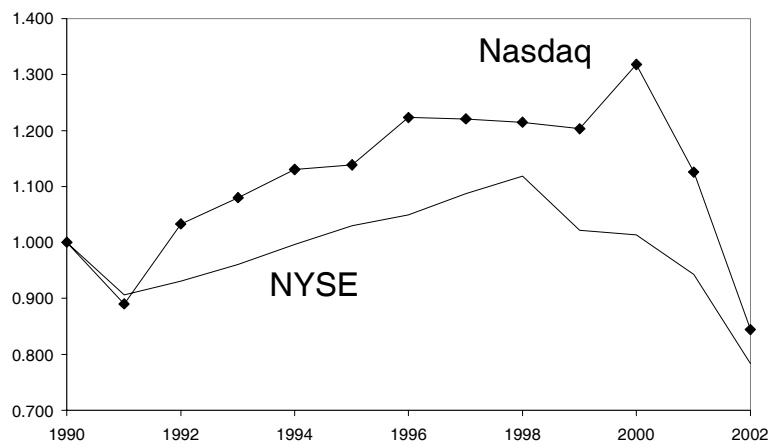




\section{Figure 4}

Vector-autoregressions for 3-variable model. Column headings indicate response variables; row headings indicate shocks. Horizontal axis shows 10-year response interval (not labeled).
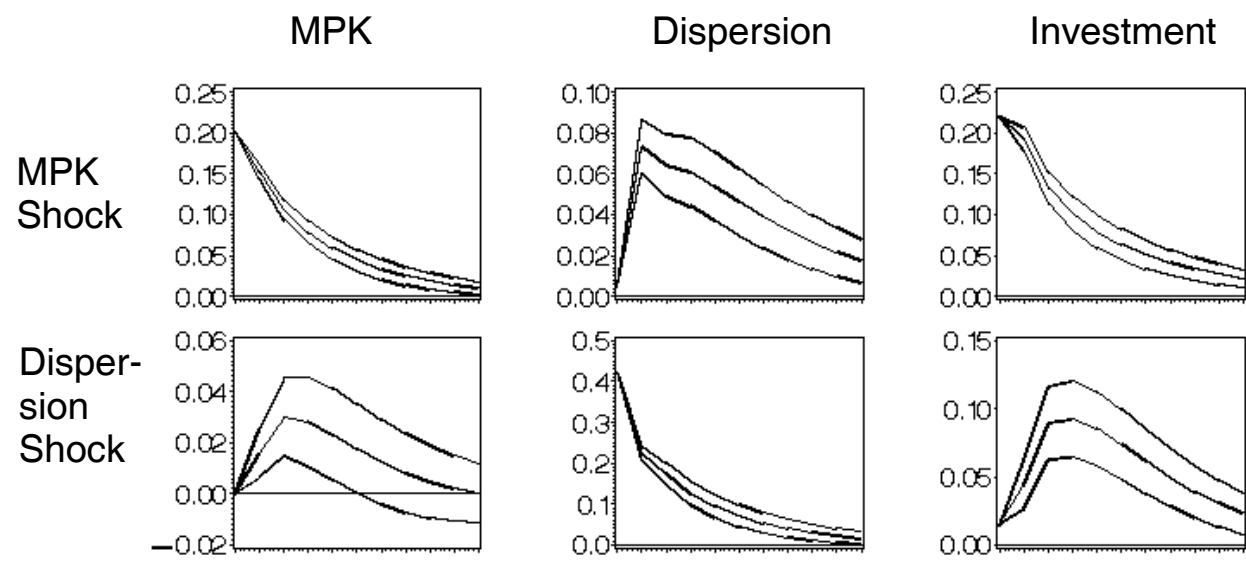

Figure 5

Vector-autoregressions for 5-variable model. Column headings indicate response variables; row headings indicate shocks. Horizontal axis shows 10-year response interval (not labeled).

MPK

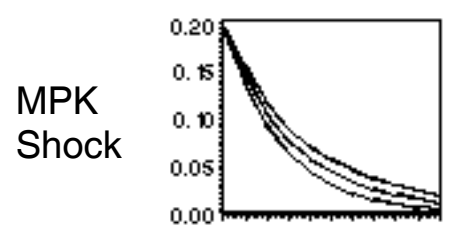

Disper-

sion

Shock
Dispersion

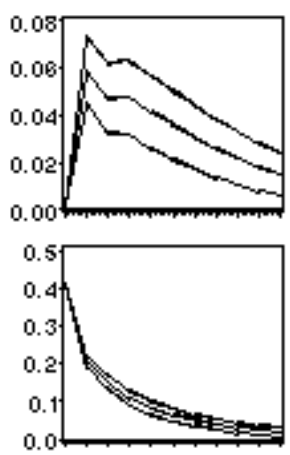

Tobin's Q

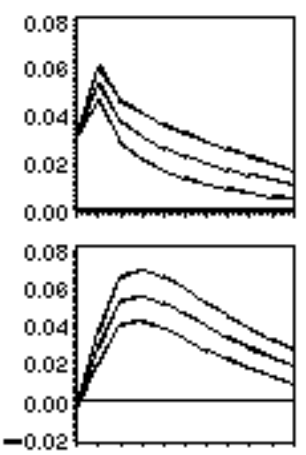

New Issues

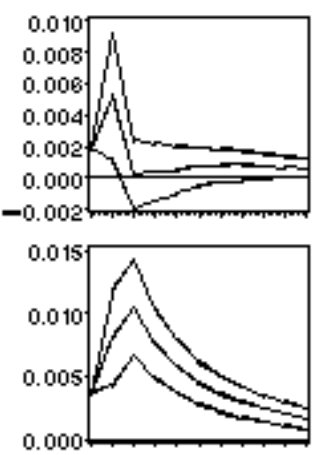

Investment

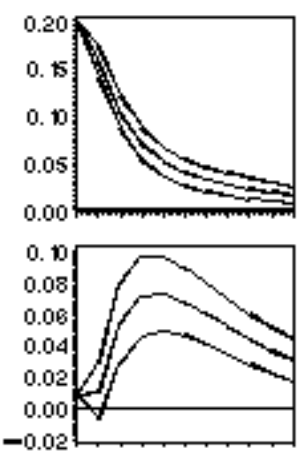

